\title{
Education at school about sexually transmitted diseases
}

\author{
K. F. H. HUNGER \\ Munster, West Germany
}

\begin{abstract}
Summary
Although sex education in West German schools started officially in 1968, a survey of 700 children aged 14 to 15 years showed that they understood more about birth control than about sexually transmitted disease (STD). This contrasts with the rising incidence of gonorrhoea and falling birth rate. There is a general lack of published information on STD and it is proposed that an international body like the IUVDT should be formed to promote the spread of information.
\end{abstract}

\section{Introduction}

The sexual activity of young people may lead to sexually transmitted disease (STD) and undesired pregnancy (Schofield, 1965). Education is an important method of combating the spread of STD and this paper considers the problem of the imbalance that exists between classroom education on contraception and instruction on STD.

\section{Sexually transmitted disease and contraception}

Venereal diseases and methods of contraception are now more relevant subjects for adolescents than they appeared to be 15 years ago when Schofield (1965) started his studies: we have rising figures, especially for gonorrhoea, yet declining birth rates (including illegitimate births) in all industrial countries. At present 70 per cent of our youngsters use contraceptives compared with 30 per cent 15 years ago (Schofield, 1965).

There seems to be less need for propaganda for the use of contraceptives, but there is an imperative demand for more and better information about STD because of its increase all over the world. If people would shield themselves against STD as con-

Presented at the 28th General Assembly of the IUVDT, Malta, April, 1975

Address for reprints: Dr. K. F. H. Hunger, D.D., 4400 Munster/ Westphalia Braunsbergstrasse 35, West Germany scientiously and efficiently as they avoid undesired pregnancies, one might expect a decline of STD similar to that of the birth rate.

Judged from a purely epidemiological point of view, the present day situation of STD resembles in some respects the conditions prevailing before the Salvarsan era, when one case of STD was statistically expected in every three or four adults.

\section{Current education at school}

Sex education at school was officially inaugurated in West Germany in 1968, and is now an obligatory teaching subject. Yet only one-third of teachers comply with the law, because they lack training for this new assignment. Even if sex lessons are given, the problem of STD is usually omitted.

The imbalance is illustrated by the results of a survey of more than 700 boys and girls, mainly 14 and 15 years old; 70 per cent. could cite at least one method of contraception, but only 28 per cent. correctly named one STD (Sigusch and Schmidt, 1973).

Sex education in any country is in a sad state if more than 70 per cent. of a sample of adolescents cannot answer a question on STD or submit a wrong answer. On the other hand, what may be achieved by public information can be seen by comparing the corresponding percentages answering a similar question on birth control; only 30 per cent. gave an incorrect answer or none.

\section{Sex education publications}

This discrepancy in knowledge regarding STD and contraception can be attributed to the general public and the educational system as well as to the teachers. To illustrate this, I screened all publications in my own library dealing specifically with human sexuality and sex education. After going through more than 150 books, comprising some 15,000 pages, I found that only $5 \cdot 2$ per cent. of their contents were devoted to contraception and less than half that to STD. This evidently does not meet our basic requirement that in sex education both themes should be given equal attention. There is a universal preoccupation with 
problems of birth control, a bias which is not justified under these circumstances. Furthermore, some writers dedicated more than one-third of their book to methods of contraception, and barely 10 per cent. to STD, while others did not mention either.

The sample of literature surveyed illustrates the imbalance that exists in various types of literature. This leads to the following observations:

(1) Although we have free access to and dissemination of knowledge concerning contraception, presentday authors think it necessary to promulgate more information about it, forgetting that STD is a probblem of which the general public, including the younger generation, is ignorant, as the growing rates of STD illustrate.

(2) It follows that there is no systematic coordination of the various topics of sex education, but a chaotic maze of contradictory opinions.

\section{Prospects}

The prospects are not as hopeless as they may appear, if we examine teacher response. Two samples comprising 100 school teachers and approximately the same number of student teachers were presented with a short questionnaire with the request to place given topics of instruction in their order of importance. As anticipated, methods of contraception were considered of paramount importance, but unexpectedly STD came second in the teachers' ranking. Teachers and students seem to be nearly unanimous in their opinion that knowledge of how to avoid STD is almost as important as knowledge of how to avoid an unwanted pregnancy. Thus, if our teachers were better equipped for sex education, they would be as effective in teaching about STD as they are now in teaching about contraception. Although the teachers rated STD second, the students placed abortion second, closely followed by STD. This slight shift may have been due to the fact that the students had just heard a lecture on abortion.
It appears that instructing the teachers how to give sex education with special reference to STD will improve their performance of that task. Our teachers are not unwilling to include STD in their sex instruction programme provided the prevailing lack of information can be remedied.

\section{Conclusions}

(1) As STD respects no national boundaries, we should strive for international co-operation between physicians and teachers.

(2) We should make systematic use of our teachers, because they are professional promulgators of a newer and better understanding of these diseases.

(3) A concerted action at the highest level, e.g. in UNESCO and WHO, might be proposed by a distinguished and internationally recognized association such as the International Union against the Venereal Diseases and Treponematoses.

(4) The first target might be the production of a small book in various languages containing:

a. Information on the history, pathology, and epidemiology of STD, specifically selected for teachers.

b. A limited number of slides for use in schools.

c. A multiple-choice programme, which may be used for self-teaching and/or to check the results of lessons about STD.

d. A leaflet designed for distribution to pupils and to be passed on by them to their families and friends for discussion.

\section{References}

SchofIELd, M. (1965) 'The Sexual Behaviour of Young People'. Longmans, London

Sigusch, V., and ScHMIDT, G. (1973) 'Jugensexualität'. Enke, Stuttgart 